\title{
Underneath it All: Soil Differences May Explain Contrasting Outcomes of Adjacent Prairie Restorations in Madison, Wisconsin
}

\author{
Krista Marshall, Nick J. Balster *, \& Alex W. Bajcz, ${ }^{a, b}$ \\ ${ }^{a}$ Department of Soil Science, University of Wisconsin-Madison, Madison, WI \\ ${ }^{b}$ Department of Biology, Drew University, Madison, NJ \\ Student:knmarshall@wisc.edu \\ Mentors:njbalster@wisc.edu*,abajc々@drew.edu
}

\begin{abstract}
The evaluation of prairie restorations tends to focus on aboveground properties such as changes in plant diversity and the encroachment of non-native species. As a result, knowledge gaps persist concerning belowground controls of restoration success. To address these gaps at a 13-year-old prairie restoration site in Madison, Wisconsin, we spatially compared soil chemical, physical, and hydrological properties in two adjacent parcels that differed markedly in response to a tallgrass prairie restoration. We hypothesized that soil properties and their heterogeneity would differ significantly between the two parcels and that these differences would help explain the divergent response. In support of this hypothesis, soil organic matter, $\mathrm{pH}$, and total nitrogen were significantly lower $(p=0.007, p<0.001$, and $p=0.006$, respectively) in the restored parcel compared to the parcel that has yet to respond to any restoration efforts. Moreover, despite no significant difference in soil average bulk density between the two parcels, the restored parcel had significantly lower sand and silt fractions overall $(p=0.039$ and $p=0.040$, respectively). In contrast, except for total nitrogen, there were no apparent differences in the spatial heterogeneity of the measured soil properties between the restored and unrestored parcels, which did not support the second hypothesis of this study. These results demonstrate the utility of measuring belowground properties when assessing unexpected outcomes of prairie restorations as well as inform future hypothesis-driven experiments to determine which soil properties impede restoration and under what circumstances.
\end{abstract}

\section{KEYWORDS}

Prairie Restoration; Bulk Density; Soil Organic Matter; Soil Properties; Soil Texture; Spatial Heterogeneity

\section{INTRODUCTION}

Prairie restoration has become a widely accepted practice for reclaiming degraded grasslands through the reintroduction and management of native plant species that promote a biodiverse and functional ecosystem. Restoration practices are also being investigated as a potential method for provisioning of ecosystem services such as nutrient cycling, water quality, carbon storage, and recreation. ${ }^{1}$ Although less than $1 \%$ of historic native prairies in the Midwestern U.S. remain today, ${ }^{2}$ programs like the Conservation Reserve Program (CRP) have contributed to the restoration of native plant communities across more than 14.8 million hectares of land in the Midwest. ${ }^{3}$ However, most research projects and evaluations of restorations continue to focus on aboveground responses, with little incorporation of belowground processes (but see ${ }^{4,5}$ ). As a consequence of this omission, the ecological trajectory of restorations is often difficult to predict and evaluate.

A review of the literature concluded that current approaches used to evaluate prairie restorations can be grouped into three broad categories: diversity-based, vegetation structure-based, and ecology-based. ${ }^{6}$ Quantitative metrics of diversity and vegetative structure include measures of species richness, the abundance of organisms at different trophic levels, the extent of vegetative cover, plant cover density, and total plant biomass — all measures focused on aboveground properties. By contrast, ecology-based approaches place greater emphasis on belowground properties, focusing on aspects such as biological interactions, nutrient cycling, and soil organic matter. Moreover, ecological approaches typically couple belowground properties explicitly with the more visible aboveground properties. Despite the usefulness of assessments that include these belowground metrics, such approaches have not been widely used to evaluate prairie restorations, perhaps in part due to their higher cost and time relative to more aboveground-focused approaches. ${ }^{7,8}$ Despite these drawbacks, incorporating belowground responses, especially those related to soil properties, into assessments of restoration efforts will likely improve our holistic understanding of the factors that determine the success or failure of these efforts.

Because soil properties often dictate the responses of plant communities ${ }^{9}$, they serve as proximate controls over plant productivity, community succession, and, ultimately, species diversity within restored ecosystems ${ }^{10}$. By extension, the spatial variability of soil properties influences the responses of plants to restoration efforts as well as the establishment of native plant species over time. ${ }^{11,12}$ For example, a study of seven different soil series in a large tallgrass prairie concluded that each series 
contained its own unique assemblage of locally abundant plant species, ${ }^{13}$ which suggests a possible relationship between variation in soil properties and the prairie plant communities they support (or co-evolutionary changes between plants and soils). Further, individual soil properties may contribute disproportionately to the establishment and growth of certain plant species. Soil carbon content, for example, has been shown to facilitate the growth of native species, whereas high levels of nitrate decreased the abundance of native flora and increased the establishment of weeds in a five-year-old tallgrass prairie in southern Minnesota. ${ }^{14}$ Another study concluded that excess soil nutrients resulting from years of soil degradation or fertilization tended to impede the establishment of native species in grassland ecosystems. ${ }^{5}$

The objective of this study was to explore whether potential differences in soil physical, chemical, and hydrologic properties or their spatial variability help explain the disparate responses of two systems to native prairie restoration: A restored 13-year-old prairie and an adjacent parcel with a history of resistance to native vegetation establishment. The hypotheses were that (1) the restored and unrestored prairies would display significant differences in soil properties (e.g., soil bulk density, soil organic matter, soil texture, volumetric water content, etc.) and (2) that the heterogeneity of soil properties in the resistant parcel would exceed that of the established prairie.

\section{METHODS AND PROCEDURES}

Study system

This study was conducted at the University of Wisconsin-Madison (UW-Madison) Biocore Prairie located in Madison, Wisconsin, USA. The property was composed of soils classified as Dodge silt-loams and Kidder silt loams, ${ }^{15}$ both of which are commonly used for agriculture in the Midwestern United States. An eleven-acre parcel of land in this region was once part of a research station used throughout the 1900s for experimental agriculture until it was phased out in the 1960s and left fallow. During this period, a portion of the property was used as disposal grounds for algal mats from a nearby lake along with construction materials and organic waste. In 1997, the entire property was incorporated into the Biocore Program at UW-Madison and subsequently managed with the goal of restoring it to a mesic tallgrass prairie for student learning and collaborative research on prairie restoration processes and its usefulness for restoring degraded environments.

In 2005, two adjacent sections of land were placed under similar tallgrass prairie restoration treatments by the UW-Madison Biocore Prairie staff. One of these, a 2-ha parcel (Area 3), continues to support a vegetative community of 50 of the 53 native species initially introduced in 2006 (Figure 1a). By contrast, an adjacent 1-ha parcel (Area 6) has yet to respond to the initial seeding or to any subsequent intervention (Figure 1b). The unrestored parcel contains few native plant species and is largely composed of stinging nettle (Uritca dioica L.), crown vetch (Securigera varia L.), reed canary grass (Phalaris arundinacea L.), and Canada thistle (Cirsium arvense L.). In an effort to combat the growth of these invasive plants, the unrestored prairie was subjected to mowing, tilling, and two growing seasons of cover crop plantings of oats in an effort to reduce the availability of soil nutrients thought to facilitate the proliferation of these aggressive taxa. However, these techniques have been unsuccessful. Thus, in an effort to explain the response differences between these adjacent parcels, their physiochemical soil properties and the spatial heterogeneity of these properties were investigated.

Thirty-two soil samples were collected during June and July of 2017 by establishing a $20 \times 20$ m grid across the two parcels (Figure 1c). This design yielded 15 grid points in the restored prairie and 17 grid points in the unrestored parcel. Of the 32 grid points, three points located in the restored prairie and two points located in the unrestored parcel lie along a transitional strip that marks a border between the parcels. Soil physical, chemical, and hydrologic properties at three depth intervals $(0-5 \mathrm{~cm}, 10-20 \mathrm{~cm}$, and $25-35 \mathrm{~cm})$ were measured at each grid point. The soil physical properties measured were penetrative resistance $(\mathrm{kPa})$, soil bulk density $\left(\mathrm{g} / \mathrm{cm}^{3}\right)$, and texture (\% sand, silt, and clay). Five soil chemical properties (total nitrogen (\%), soil organic matter (\%), soil $\mathrm{pH}$, available phosphorus ( $\mathrm{ppm})$, and exchangeable potassium ( $\mathrm{ppm})$ ) were used to evaluate soil fertility. Finally, volumetric water content was measured at each point 72 hours after approximately $2 \mathrm{~cm}$ of rainfall at the property.

\section{Penetrative resistance}

The soil penetrative resistance, or the force needed to drive a cone penetrometer into a soil pedon, ${ }^{16}$ was measured over two days in June approximately $30 \mathrm{~cm}$ north of each grid point. This metric was used as a proxy for soil structure and relative density as well as to determine the presence of compacted layers within the soil profile. ${ }^{17}$ The cone of the penetrometer was first pressed vertically into the surface residue until it was completely buried. The sliding hammer was then dropped repeatedly at 5-cm increments until a total depth of $35 \mathrm{~cm}$ was reached, gauged by graduations on the instrument. At each increment, the number of hammer drops required was recorded. The data were collected over the course of two days to minimize the effect of changes in moisture content and in soil macrofauna. ${ }^{18}$ An Energy-Work theorem developed by Halliday and Resnick (1963) was used to calculate the work done by the soil to resist penetration and, subsequently, the soil penetrative resistance using the following equation: ${ }^{19}$ 


$$
\mathrm{R}=\frac{\mathrm{W} / \mathrm{d}}{\mathrm{SA}_{\text {cone }}}
$$

Equation 1.

where soil penetrative resistance $(\mathrm{R})$ in $\mathrm{kPa}$ was calculated for each $5 \mathrm{~cm}$ increment by dividing the work term (W) by the approximate incremental distance traveled by the penetrometer cone $(\mathrm{d})$ and then by the surface area of the cone $\left(\mathrm{SA}_{\text {cone). The }}\right.$ work done on the soil was calculated by assuming that all the kinetic energy transfers from the hammer to the cone penetrometer as the hammer strikes the plate and movement stops, i.e., the soil resists penetration by the penetrometer.

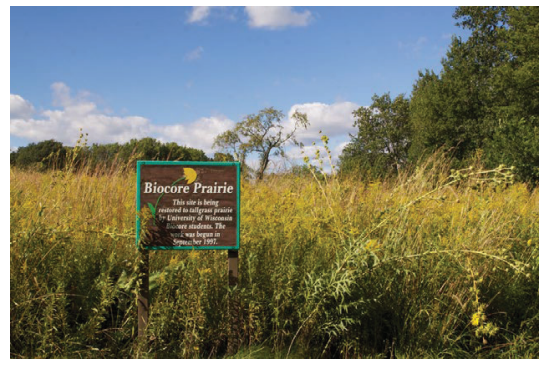

(a)

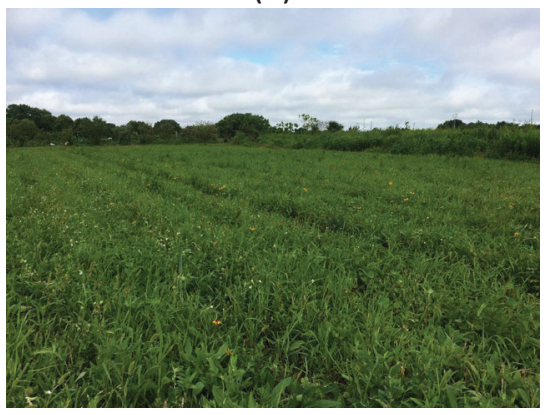

(b)

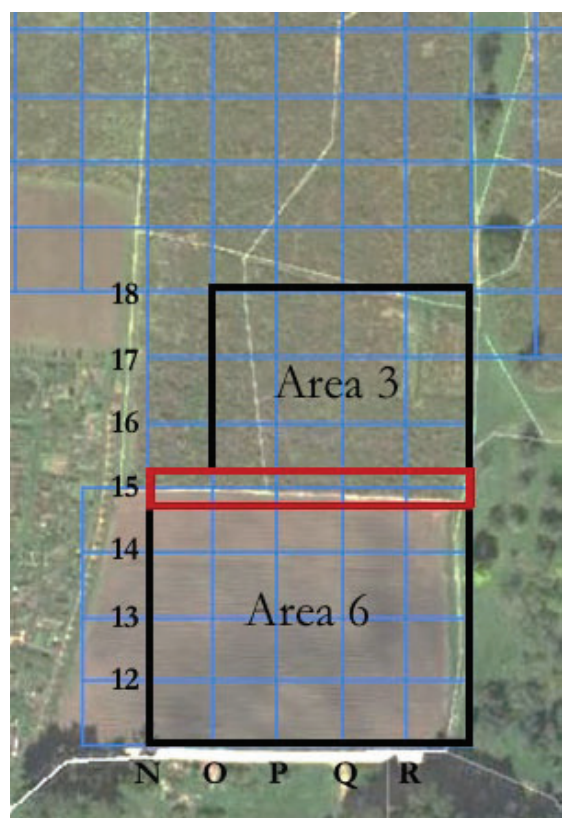

(c)

Figures 1a-c. Satellite view of the study site in Madison, Wisconsin, USA (1c), acquired by the University of Wisconsin-Madison Biocore in 1997, showing the property prior to prairie restoration. Area 3 is the successfully restored parcel studied here (1a), whereas Area 6 is the parcel that has not responded to restoration efforts (1b). A transitional strip between the restored and unrestored parcels of the prairie is delineated in red. The leftmost three points within this strip were deemed to lie in Area 6 (unrestored), whereas the other two were deemed to lie in Area 3 (restored).

\section{Soil bulk density}

Bulk density (BD) describes the ratio of the oven-dried mass of soil particles to the volume of the soil, including pore space. ${ }^{20}$ Soil samples were taken during July over two days at each grid point using a 3.5 inch diameter soil core to a depth of $40 \mathrm{~cm}$ and processed for their bulk density over three depth increments $(0-5,10-20$, and $25-35 \mathrm{~cm})$. The samples were cut into the separate depth increments and placed in an oven $\left(104^{\circ} \mathrm{C}\right)$ to dry for 72 hours to achieve a constant mass. Once the samples reached a constant mass, the oven-dry mass was divided by the volume of the increment to determine bulk density.

\section{Soil texture}

The relative percentages of sand, silt, and clay define a soil's texture. Samples were taken in June from the 10-20 cm depth range approximately $15 \mathrm{~cm}$ from each grid point. After the samples were collected, they were oven-dried (at $104^{\circ} \mathrm{C}$ ) and preserved. The samples were placed in hydrogen peroxide to help remove soil organic matter before the textural analysis. During this process, the samples were heated to $60^{\circ} \mathrm{C}$ to help catalyze the reaction (modified from ${ }^{21}$ ). We assume the majority of the organic matter was removed but we did not verify this assumption. To eliminate the possibility of including soil particles outside the sand, silt, and, clay size range, approximately $40 \mathrm{~g}$ of each sample was gently ground using a mortar and pestle until the samples were able to pass through a 2-mm sieve and subsequently weighed. After this was done, soil texture was determined using the standard hydrometer method. Hydrometer readings for settling of the sand fraction were taken at 40 seconds. Readings were taken again at four hours to measure the amount of clay particles in suspension. In addition to analysis of particle size fractions, a textural triangle was used to classify each soil sample.22 


\section{Soil fertility}

Properties commonly used to describe soil fertility include soil organic matter (SOM), total nitrogen (N), available phosphorus $(\mathrm{P})$, exchangeable potassium $(\mathrm{K})$, and soil $\mathrm{pH} .{ }^{14,23-24}$ Soil samples from the $10-20 \mathrm{~cm}$ depth range were taken at each grid point in June 2017. Each sample was then dried to $104^{\circ} \mathrm{C}$, sieved to exclude any particles $>2 \mathrm{~mm}$ in diameter, and sent to the UW Soil and Forage Lab for analysis. Methods used to test these properties were Loss on Ignition for SOM, total Kjeldahl nitrogen for total N, Bray 1 extraction for P \& $\mathrm{K}$, and a 1:1 water:soil paste to measure $\mathrm{pH}$.

\section{Volumetric water content}

The volumetric water content at a depth of $10 \mathrm{~cm}$ was calculated at each grid point $72 \mathrm{~h}$ after a $2 \mathrm{~cm}$ rainfall in July. A ThetaProbe was used to measure the volumetric water content at each grid point, reported on a percentage basis. ${ }^{25}$ The Thetaprobe applies a $100 \mathrm{MHz}$ signal through a transmission line whose impendence changes as the impendence of the soil changes. These changes are converted to voltage readings that are proportional to the volumetric soil moisture content (in percent ${ }^{25}$ ). The 72 -hour sample was taken to assess soil water drawdown after a period of evapotranspirative loss.

\section{Analyses}

The data were explored and analyzed using $\mathrm{R}$ version 3.3.3. ${ }^{26} \mathrm{It}$ is a common assumption that soil properties will be autocorrelated. To account for this interrelatedness, a correlation matrix was generated (Table 1). Soil organic matter and total $\mathrm{N}$ were highly correlated (Pearson's $r=0.972$ ). Additionally, the sand and silt fractions were strongly correlated (Pearson's $r=-0.918$ ). These correlations were considered when evaluating the results; most soil properties do not exist in isolation and are frequently interrelated to other soil properties. Properties that were measured at a single depth of 10-20 cm were analyzed using ANOVA. For soil properties anticipated to vary over depth (i.e., soil penetrative resistance, bulk density, and volumetric water content), mixed-effect ANCOVA was used.

\begin{tabular}{|c|c|c|c|c|c|c|c|c|c|c|}
\hline & $\begin{array}{c}\text { Sand } \\
\%\end{array}$ & $\begin{array}{c}\text { Clay } \\
\% \\
\end{array}$ & SOM & $\mathbf{N}$ & $\mathbf{P}$ & $\mathbf{K}$ & $\mathrm{pH}$ & $\begin{array}{c}\text { Bulk } \\
\text { density }\end{array}$ & $\begin{array}{c}\text { VMC } \\
\text { at } 72 \mathrm{~h}\end{array}$ & $\begin{array}{c}\text { Silt } \\
\%\end{array}$ \\
\hline 1 & 1 & & & & & & & & & \\
\hline 2 & -0.432 & 1 & & & & & & & & \\
\hline 3 & 0.543 & -0.215 & 1 & & & & & & & \\
\hline 4 & 0.519 & -0.280 & 0.972 & 1 & & & & & & \\
\hline 5 & -0.367 & -0.038 & 0.028 & 0.098 & 1 & & & & & \\
\hline 6 & -0.339 & 0.004 & 0.083 & 0.169 & 0.755 & 1 & & & & \\
\hline 7 & 0.558 & -0.189 & 0.292 & 0.286 & -0.061 & -0.097 & 1 & & & \\
\hline 8 & -0.037 & 0.270 & -0.430 & -0.422 & -0.222 & -0.092 & -0.065 & 1 & & \\
\hline 9 & -0.258 & 0.175 & -0.018 & -0.067 & 0.092 & 0.081 & -0.220 & -0.354 & 1 & \\
\hline 10 & -0.918 & 0.039 & -0.507 & -0.452 & 0.424 & 0.374 & -0.535 & -0.078 & 0.209 & 1 \\
\hline
\end{tabular}

Table 1. Correlation matrix of Pearson's $r$ values used to quantify the strength of correlations between soil properties measured in this study. The order of properties across columns is the same as down rows.

ANOVA was used to determine the statistical significance of the differences in soil properties between the restored and unrestored parcels of the prairie. The ANOVA models for sand, silt, clay, SOM, N, P, K, and pH were confirmed to exhibit homoscedasticity and approximate linearity and to have normally distributed residuals. Plots of standardized residuals versus fitted values, Q-Q plots, leverage plots, and histograms were used to validate these assumptions. Additionally, data were analyzed with and without prospective outliers and deemed non-influential. Probability values $<0.05$ were considered significant, and values $<$ 0.1 but $>0.05$ were deemed marginally significant. Graphs were produced using goplot 2.27 Heat maps were used to qualitatively assess our second hypothesis of whether the spatial heterogeneity of the soil properties listed above differed noticeably between the two parcels. 
Properties that varied over depth were analyzed using linear mixed-effects ANCOVA (analysis of covariance) using the $l m e 4,28$ ImerTest, ${ }^{29}$ and pbkertest ${ }^{30}$ packages. Bulk density and volumetric water content were sampled at three depth increments $(0-5,10-20$, and 25-35 cm), yielding 96 data points, 32 at each depth increment. Penetrative resistance was calculated at seven depths at each grid point $(5,10,15,20,25,30$, and $35 \mathrm{~cm})$, resulting in 224 data points. Mixed-effects ANCOVA was used to model differences between the restored and unrestored prairies across multiple depths. The grid point was the grouping factor for these mixedeffects ANCOVAs, and the fixed factors for each model were area, depth, and the area-by-depth interaction. Prospective outliers were analyzed and deemed non-influential. Probability values $<0.05$ for the interaction term were used to conclude that a soil property changed with depth at different rates between the restored and unrestored parcels of the prairie.

\section{RESULTS}

We used the ANOVA results to discern whether the soil properties of the two sites differed significantly. The mean values for soil $\mathrm{pH}$ and organic matter were significantly different between the restored and unrestored parcels of the prairie at $\alpha=0.05$ (Table 2). The mean soil $\mathrm{pH}$ in the restored prairie was significantly lower $(\mathrm{pH}=6.6 \pm 0.07)$ than the average soil $\mathrm{pH}$ across the unrestored prairie $(7.1 \pm 0.06$; Table 2$)$. The restored parcel of the prairie also had significantly lower SOM $(2.49 \% \pm 0.129 \%)$ than the unrestored parcel $(4.24 \% \pm 0.550 \% ; p=0.007$; Table 2$)$. Total nitrogen, highly correlated with SOM in our data, was also significantly higher in the unrestored parcel of the prairie $(0.279 \% \pm 0.033 \%)$ than in the restored parcel $(0.171 \% \pm 0.01 \% ; p$ $<0.006$; Table 2; Figure 2). A qualitative assessment of a heat map generated for total nitrogen (Figure 2) suggests that the restored parcel of the prairie was more homogenous for this soil property than the unrestored parcel. However, heat maps generated for all other soil properties (not presented) did not show distinctly different levels of heterogeneity between the two parcels.

\begin{tabular}{ccccc|cccc|cccc}
\hline \multicolumn{5}{c|}{ Unrestored } & \multicolumn{5}{c|}{ Restored } & \multicolumn{4}{c}{ ANOVA results } \\
\hline & Min & Mean & Max & SE & Min & Mean & Max & SE & Area & $\beta_{0}$ & t & $p$ \\
\hline Sand & 15.8 & 23.3 & 48.6 & 2.15 & 15.1 & 33.0 & 63.1 & 3.73 & 9.65 & 23.3 & 7.17 & $\mathbf{0 . 0 3 9}$ \\
Silt & 33.5 & 53.9 & 68.2 & 2.17 & 20.5 & 45.2 & 72.8 & 3.26 & -8.64 & 53.9 & -2.15 & $\mathbf{0 . 0 4 0}$ \\
Clay & 9.90 & 22.8 & 31.9 & 1.50 & 12.1 & 21.8 & 29.1 & 1.18 & -1.01 & 22.8 & -0.531 & 0.599 \\
\hline SOM & 1.60 & 2.49 & 3.50 & 0.130 & 2.30 & 4.24 & 10.4 & 0.550 & 1.75 & 2.49 & 5.72 & $\mathbf{0 . 0 0 7}$ \\
N & 0.0590 & 0.171 & 0.239 & 0.010 & 0.156 & 0.279 & 0.690 & 0.0330 & 0.108 & 0.171 & 2.98 & $\mathbf{0 . 0 0 6}$ \\
P & 41.0 & 76.3 & 142 & 7.81 & 30.0 & 83.7 & 173 & 10.5 & 7.37 & 76.3 & 7.85 & 0.585 \\
K & 62.0 & 100 & 173 & 7.90 & 45.0 & 145 & 480 & 29.2 & 44.5 & 100 & 4.30 & 0.174 \\
pH & 6.1 & 6.6 & 7 & 0.07 & 6.7 & 7.1 & 7.5 & 0.055 & 0.438 & 6.6 & 106 & $<\mathbf{0 . 0 0 1}$ \\
\hline
\end{tabular}

Table 2. Soil physical (top half) and fertility-related (bottom half) property metadata (means, ranges, and SEs) from the $10-20 \mathrm{~cm}$ depth interval of the restored and unrestored parcels of the Biocore Prairie in Madison, Wisconsin, USA. ANOVA (right side) was used to evaluate the strength of differences in soil properties

between the two land parcels. The $\mathrm{t}$ and $p$ values in the table are for the Area main-effect terms (i.e., these have been omitted for the intercept terms), and significant differences at $\alpha=0.05$ are noted in bold.

Analysis of the sand, silt, and clay fractions revealed that the soil texture varied between the restored and unrestored parcels of the prairie at the 10-20 cm depth (Table 2; Figure 3). While the mean clay contents of the restored $(22.8 \% \pm 0.52 \%)$ and unrestored $(21.8 \% \pm 1.18 \%)$ parcels were not significantly different $(p=0.599)$, the mean sand fraction in the restored parcel of the prairie $(23.3 \% \pm 2.15 \%)$ was significantly lower $(p=0.039)$ than in the unrestored parcel $(33.0 \% \pm 3.73 \%$; Table 2$)$. Additionally, the variance in the sand fraction data in the unrestored parcel was greater than in the restored parcel of the prairie (Figure 3). The majority of the soil samples $(73 \%)$ from the restored prairie were classified as silt loams, ${ }^{30}$ whereas no one textural class dominated the unrestored prairie; soils there were classified as silt loams (41\%), loams (35\%), and clay and sandy loams $(12 \%$ each).

Mixed-effect ANCOVA was used to assess whether soil properties varied significantly with depth as well as whether these rates of change differed between these two adjacent parcels of the prairie (Table 3). The mean bulk density across all depths between the restored and unrestored parcels of the prairie did not differ significantly (Table 3). However, bulk density increased faster with depth in the unrestored prairie than in the restored prairie ( $p=0.048$; Figure 4; Table 3). The mean soil penetrative resistance between the restored and unrestored prairies was not significantly different $(p=0.129)$ throughout the $35 \mathrm{~cm}$ soil profile sampled (Table 3). Although these parcels did not differ significantly for this property, the standard error in the unrestored parcel increased dramatically after a depth of $20 \mathrm{~cm}$ (data not shown), whereas standard error values in the restored prairie tended to be less variable throughout the soil profile. Volumetric water content sampled 72 hours after a rainfall event did not significantly differ between the restored and unrestored parcels of the prairie $(p=0.253$; Table 3 ). 


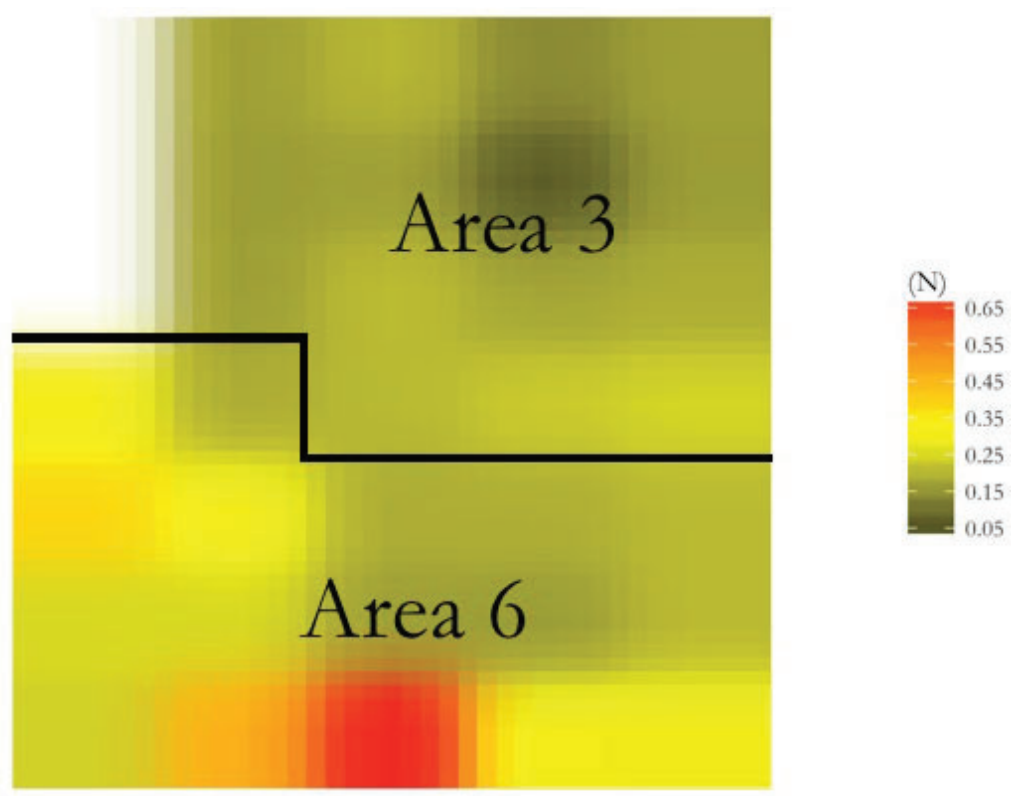

Figure 2. A heat map of total nitrogen (\% Kjeldahl $\mathrm{N}$ by mass) for the unrestored parcel (Area 6$)$ of the Biocore prairie in Madison, Wisconsin, USA versus the restored parcel (Area 3). The 32 grid points sampled (see Figure 1) were interpolated to smooth the heat map, producing a gradient of colors based on total nitrogen value (highest $=$ red, lowest $=$ green)

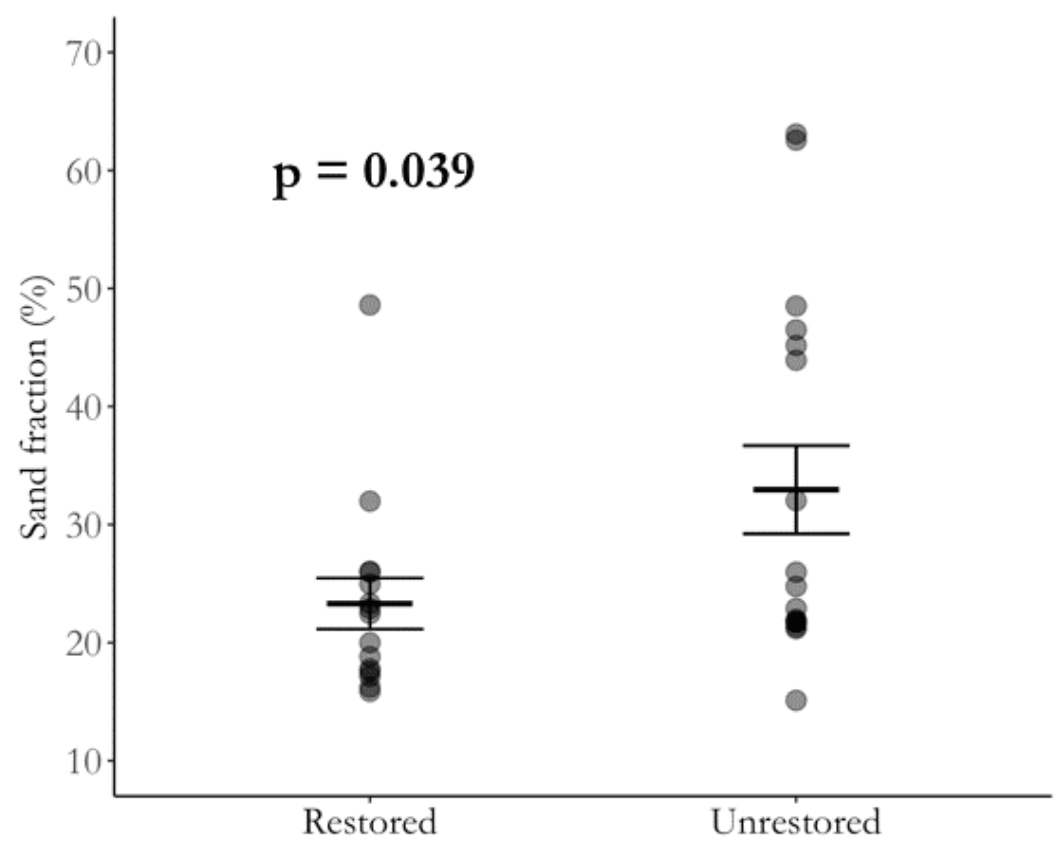

Figure 3. Data on the sand fraction of soils (y axis) from the successfully restored and unrestored parcels ( $\mathrm{x}$ axis) of the Biocore prairie in Madison, Wisconsin, USA. The thick horizontal line represents the mean values for the two parcels, and the error bars are one standard error. Points are semi-transparent; darker colors indicate where points are overplotted. 


\begin{tabular}{ccccccc}
\hline & & $\boldsymbol{\beta}$ & ddf & SE & t & $p$ \\
Penetrative & Intercept & 711.4 & 101.3 & 290.8 & 2.446 & 0.179 \\
resistance & Depth & -157.4 & 101.3 & 399.0 & -0.395 & 0.694 \\
& Area & 273.7 & 204.5 & 204.5 & 5.384 & $<0.001$ \\
& Area $\times$ depth & 106.3 & 204.5 & 204.5 & 1.524 & 0.129 \\
\hline Bulk & Intercept & 0.6847 & 89.16 & 0.03870 & 17.69 & $<0.001$ \\
density & Depth & -0.09390 & 89.16 & 0.05310 & -1.769 & 0.080 \\
& Area & 0.2517 & 62.00 & 0.01490 & -16.94 & $<0.001$ \\
& Area $\times$ depth & 0.04110 & 62.00 & 0.02040 & -2.015 & $\mathbf{0 . 0 4 8}$ \\
\hline Volumetric & Intercept & 35.39 & 87.36 & 1.505 & 25.52 & $<0.001$ \\
Water & Depth & 0.4305 & 87.36 & 2.065 & 0.208 & 0.853 \\
Content & Area & 0.6900 & 62.00 & 0.5660 & 1.268 & 0.210 \\
at 72 h & Area $\times$ depth & -0.8959 & 62.00 & 0.7766 & -1.154 & 0.253 \\
\hline
\end{tabular}

Table 3. Mixed-effect ANCOVA results used to determine whether soil properties that varied with depth (i.e., penetrative resistance, bulk density, and volumetric water content) did so differently in the restored versus unrestored parcels of the Biocore prairie. The $p$ value for the Area $\times$ depth interaction term was used to determine whether these rates of change with depth differed significantly between the two parcels. Significant differences in this regard are noted in bold.

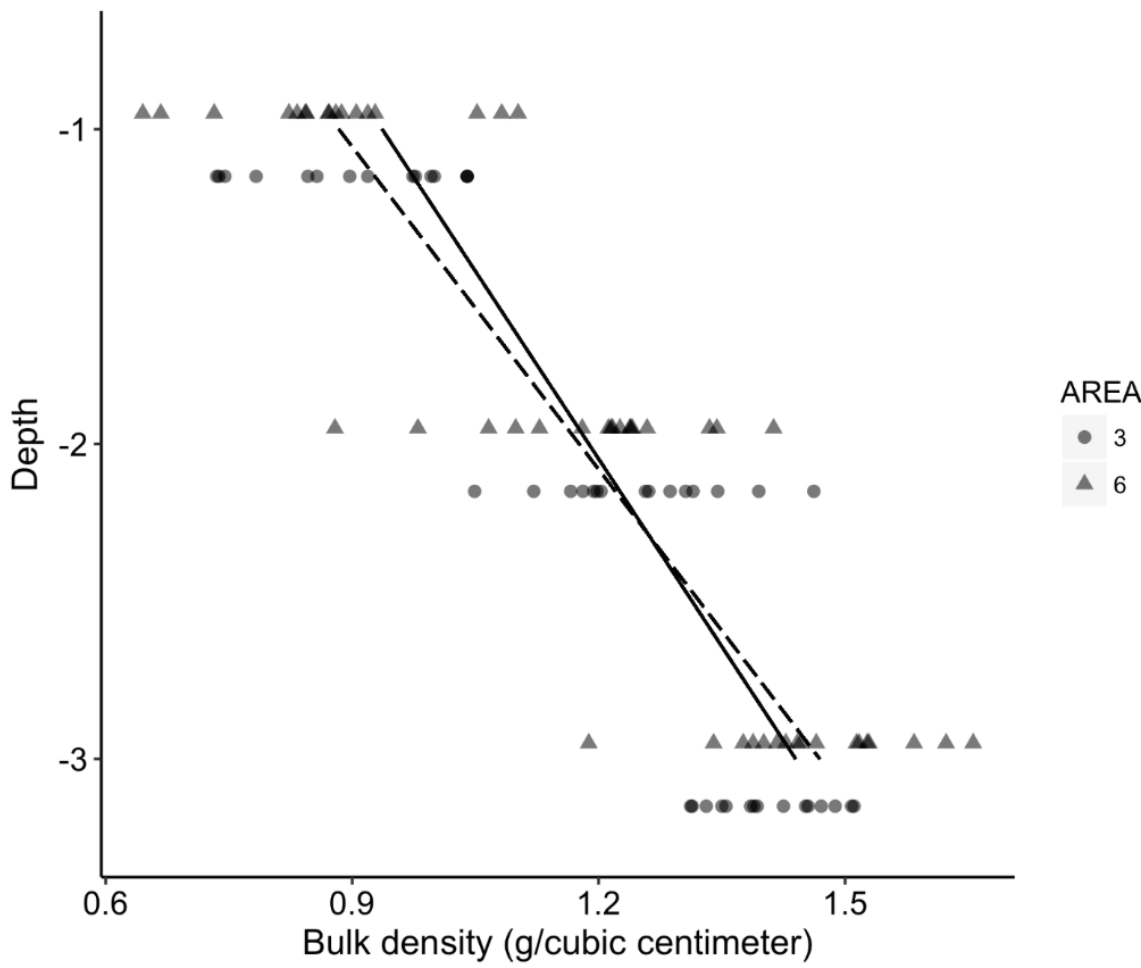

Figure 4. Bulk density ( $\mathrm{x}$ axis) data by depth interval (y axis) in the unrestored parcel of the prairie (Area 6; dashed line) and in the restored parcel (Area 3; solid line) of the Biocore prairie in Madison, Wisconsin, USA. All grid points were sampled at depths of 0-5 cm (labeled 1), 10-20 cm (labeled 2), and 25-35 cm (labeled 3) and plotted as either circles (restored parcel) or triangles (unrestored parcel). Points have been offset vertically at each depth interval by Area. Points are semitransparent; darker colors indicate where points are overplotted.

\section{DISCUSSION}

In support of our first hypothesis, soil properties differed between the restored prairie and the parcel that has been resistant to restoration (unrestored) at the Biocore property. On average, the unrestored section had higher soil organic matter, total nitrogen, and percent silt and sand than the restored section, as well as a more alkaline soil $\mathrm{pH}$. The difference in soil organic matter was particularly noteworthy because it contradicts prevailing research suggesting that prairie restoration increases soil organic matter over time. ${ }^{32-36}$ Alternatively, the difference may be a legacy effect from prior anthropogenic disturbances that occurred at this site. The unrestored parcel also had a higher total nitrogen content overall, a nutrient that, at excessive levels, is expected to favor the encroachment of non-native species ${ }^{14}$, and a higher soil $\mathrm{pH}$, which mediates the availability of nitrogen and other key nutrients. ${ }^{24}$ 
However, except for total nitrogen, the heterogeneity of the measured soil properties did not differ markedly between the restored and unrestored parcels. Research on the relationship between resource heterogeneity, particularly that of nitrogen, and the establishment and diversity of native species has been mixed, with some studies finding positive relationships ${ }^{37}$ and others, including ours, suggesting less influence of soil heterogeneity. 38,39 These data suggest that the mean differences in soil properties are likely more important than the heterogeneity of these properties in helping to explain the disparity in restoration success between the two parcels in the Biocore prairie.

The unrestored section of the prairie contained almost twice as much soil organic matter as the restored prairie, which is inconsistent with studies finding an accumulation of organic matter as restored prairies develop. ${ }^{36}$ Our results, however, corroborate an alternate body of research that challenges assumptions concerning changes in organic matter during prairie restoration. Some studies have observed that prairie restorations have little effect on soil organic matter ${ }^{39,40}$ or that concentrations in restorations may even decrease over time. ${ }^{41}$ For example, a recent study of urban grasslands in Illinois found that soil organic matter at a long-term restoration site was significantly lower (4.7\%) than at an unmanaged comparison site (6.1\%). ${ }^{41}$ These conflicting results suggest multiple competing factors (e.g., soil microbial activity and abiotic changes) may drive changes in soil organic matter during the restoration of prairie ecosystems. Therefore, controlled experiments may be needed to fully understand how and why soil organic matter changes as restored prairies develop.

Despite efforts to combat the growth of non-native vegetation through nitrogen-reducing management practices in the unrestored section of the prairie, total nitrogen, a nutrient expected to increase the success of invasive species in prairie ecosystems ${ }^{14}$, was still higher in the unrestored section than in the restored section. It is possible that high nitrogen content in the unrestored section has permitted invasive species to outcompete native plants there. In addition, plant-available forms of nitrogen are attracted to the charged sites on soil organic matter, ${ }^{42}$ a soil property that was also found to be higher in the unrestored section than in the restored section and which was highly correlated with total nitrogen in this study. Thus, the higher soil organic matter content in the unrestored section may have facilitated a positive feedback with respect to soil nitrogen availability, allowing increased growth of invasive flora and decreased establishment of native flora.

Soil $\mathrm{pH}$, a controlling factor in the availability of essential plant nutrients, ${ }^{24}$ was lower in the restored section of the prairie relative to the unrestored section, which may be central to explaining the contrasting responses between the two sections. Most macroand micronutrients, including plant-available forms of nitrogen, are more readily available for plant uptake at soil $\mathrm{pH}$ values between 6.0 and $7.0^{43}$. All $\mathrm{pH}$ values in the restored section fell within this range, whereas the majority of soil $\mathrm{pH}$ values in the unrestored parcel were higher than this range. A similar study of a successfully restored tallgrass mesic prairie approximately 30 $\mathrm{km}$ from our study site also found that annual measurements of soil $\mathrm{pH}$ ranged from approximately 6.0 to $6.3,{ }^{44}$ consistent with the results for the restored section presented here. Based on these studies, although we did not measure the availability of all relevant plant nutrients, we speculate that the higher $\mathrm{pH}$ range in the unrestored section may thus be prohibiting access to essential nutrients for native plant species. An experimental decrease in $\mathrm{pH}$ in the unrestored section (e.g., via sulfur application ${ }^{45}$ ) could be used to test whether a reduction in $\mathrm{pH}$ would indeed facilitate the establishment of native prairie flora there.

While considering soil $\mathrm{pH}$ in relation to the availability of essential nutrients is appropriate, evaluating how soil $\mathrm{pH}$ relates to microbial activity may yield a more holistic understanding of varied restoration success at sites like the Biocore prairie. For example, the establishment and activity of soil microbial communities is particularly sensitive to changes in soil $\mathrm{pH} .46,47 \mathrm{~A}$ recent study of a prairie restoration in Kansas found that soil microbial biomass was negatively correlated with soil $\mathrm{pH}$ (Pearson's $\mathrm{r}=$ 0.83). ${ }^{47}$ Although soil microbial analyses were not included in the present study, other studies have indicated that microbial biomass and diversity both increase throughout a prairie restoration and could serve as useful metrics for assessing progress. 47-50 Despite this, soil microbial characteristics are rarely incorporated into restoration evaluations, largely due to the time and cost associated with quantifying them. ${ }^{6}$ However, given the soil $\mathrm{pH}$ differences observed in this study, these measurements may be informative for understanding the disparate restoration outcomes we observed.

Soil texture influences a suite of soil properties, including water-holding capacity and the size of carbon and nitrogen pools, and thus contributes to the success of prairie restorations. ${ }^{39}$ The sand fraction in the unrestored section of the prairie was greater than in the restored prairie, and this section also had greater variation in soil textural classes than the restored section. In contrast, just one soil textural class dominated the restored section. An analogous study of a restored mesic tallgrass prairie in southern Wisconsin ${ }^{44}$ found their site to be largely composed of silt loams, similar to the successfully restored parcel in the current study. In addition, the same study ${ }^{44}$ found that soil properties ( $\mathrm{pH}, \mathrm{NPK}$, soil organic matter, and drainage) at that restored site approached similar values as those observed in other nearby remnant prairies. Taken together, the above results suggest that the textural properties of the unrestored section of the Biocore prairie may be further limiting the establishment of a native plant community there. 
Given the results of the textural analysis, we expected that bulk density would be lower in the restored prairie than in the unrestored section. However, the two sections did not differ in this physical property. This result concurs with a similar finding in another study conducted in southern Wisconsin, ${ }^{40}$ although it conflicts with several past restoration studies that observed lower bulk densities in restored prairies. ${ }^{50-52}$ For example, the results of a six-year study of a restored prairie found bulk density to increase in the $0-10 \mathrm{~cm}\left(1.25\right.$ to $\left.1.45 \mathrm{~g} / \mathrm{cm}^{3}\right), 20-35 \mathrm{~cm}\left(1.2\right.$ to $\left.1.3 \mathrm{~g} / \mathrm{cm}^{3}\right)$, and $35-50 \mathrm{~cm}\left(1.18\right.$ to $\left.1.4 \mathrm{~g} / \mathrm{cm}^{3}\right)$ depth intervals. ${ }^{33}$ The similarity in mean bulk density between the sections in our study may be partially explained by two contrasting effects involving marked differences in soil organic matter and sand content. Increases in soil organic matter tend to decrease bulk density, ${ }^{4}$ whereas increasing sand content tends to have the opposite effect. ${ }^{55}$ The unrestored section had significantly higher soil organic matter, which would suggest a lower bulk density. However, the greater sand fraction in the unrestored section may have offset this effect, resulting in a nonsignificant difference overall in bulk density between the restored prairie and the section so far resistant to restoration. Therefore, we contend that bulk density may not be a reliable diagnostic of restoration success by itself because it is fundamentally interconnected with other belowground properties such as soil organic matter. ${ }^{56}$

In general, the results presented here do not corroborate the idea that resource heterogeneity drives species diversity in grassland ecosystems ${ }^{37}$. However, some soil properties, particularly total nitrogen, were somewhat more heterogeneous in the unrestored section than in the restored section of the prairie. The heat map of total nitrogen (Figure 2) appears to show that not only was the unrestored section qualitatively more heterogeneous than the restored section, but it also contained the largest nitrogen values overall. While some studies have found both species richness and diversity to increase with nutrient resource heterogeneity, ${ }^{57-58}$ other studies suggest that the raw availability of a resource itself may be a better predictor of how similar the restored plant community becomes to a native prairie. ${ }^{38,39}$ For example, a restoration of a lowland agricultural field in Kansas indicated that establishment of non-native vegetation was lowest in treatments with lower nitrogen availability. ${ }^{39}$ The authors of that study concluded that total nitrogen availability in each treatment was a better predictor of the resulting community composition than was the spatial heterogeneity of nitrogen. ${ }^{39}$ Although total nitrogen heterogeneity was analyzed using a qualitative approach, more rigorous quantitative analyses may reveal a more conclusive explanation for the disparate outcomes at the Biocore property.

\section{CONCLUSIONS}

The disparate outcomes observed in adjacent parcels within a 13-year old prairie restoration provided an opportunity to assess the explanatory power of differences in soil properties and their spatial heterogeneity. Mean soil organic matter and bulk density, two metrics that are commonly used to measure restoration progress, did not corroborate past research that suggests prairie restoration decreases bulk density and increases soil organic matter. Several other soil properties (i.e., soil pH, \% sand, \% silt, and total nitrogen) not traditionally included in restoration progress evaluations differed between the restored parcel and the one resistant to restoration efforts. In addition, this study found that except for total nitrogen, the heterogeneity of the measured soil properties was not noticeably different between the restored and unrestored parcels. This finding did not support our second hypothesis and does not support the assumed causal relationship between resource heterogeneity and species diversity. Nevertheless, we suspect that the differences in the soil properties we observed are likely contributing to the contrasting levels of restoration success at this site and, as such, advocate for including soil properties in the study of aboveground outcomes of prairie restorations. Documented relationships between changes in soil hydraulic properties ${ }^{59}$ and soil microbial communities ${ }^{47}$, for example, and the establishment of prairie plant communities demonstrate the usefulness of coupling these above- and belowground facets of prairies under restoration.

\section{ACKNOWLEDGMENTS}

The authors thank the Friends of the Lakeshore Nature Preserve for sponsoring the Student Engagement Grant received by the first author of this study. Many thanks also to Dr. J. Batzli and S. McGee from the UW Biocore program for offering the Biocore prairie as a study site. Finally, we would like to acknowledge undergraduates D. Dryer, L. Johnson, and R. Aschenbrenner for their enthusiasm and willingness to spend hot summer days lugging around sampling equipment and helping to take measurements for this project.

\section{REFERENCES}

1. Dodds WK et al (2008) Comparing ecosystem goods and services provided by restored and native lands. In : Bioscience Magazine 58(9) : 837-845. https://doi.org/10.1641/B580909

2. Kessler R (2012) In Midwest, bringing back native prairies yard by yard. In: Yale Environment 360. https:// e360.yale.edu/features/in_us_midwest_restoring_native_prairie_ecosystems_kessler.

3. Kindscher K, Tieszen LL (1998) Floristic and soil organic matter changes after five and thirty-five years of native tallgrass prairie restoration. Restoration Ecol 6:181-196. doi: 10.1111/j.1526-100X.1998.06210.x

4. Wells AJ, Balster NJ, VanWychen S, Harrington J (2008) Differences in belowground heterogeneity within a restoration of a dewatered reservoir in southwestern wreisconsin. Restoration Ecol 16:678-688. doi: 10.1111/j.1526-100X.2008.00487.x 
5. Heneghan L, Miller SP, Baer S, Callaham MA, Montgomery J, Pavao-Zuckerman M, Rhoades CC, Richardson S (2008) Integrating soil ecological knowledge into restoration management. Restoration Ecol 16:608-617. doi: 10.1111/j.1526100X.2008.00477.x

6. Ruiz-Jaen MC, Mitchell Aide T (2005) Restoration success: How is it being measured? Restoration Ecol 13:569-577. doi: 10.1111/j.1526-100X.2005.00072.x

7. Chambers JC, MacMahaon JA, Wade GL (1992) Differences in successional processes among biomes: importance in obtaining and evaluating reclamation success. Northeastern Forest Experimental Station, United States Department of Agriculture Forest Service, Radnor, Pennsylvania

8. Herrick JE (2000) Soil quality: an indicator of sustainable land management? Appl Soil Ecol 15:75-83. doi: 10.1016/S09291393(00)00073-1

9. Callaham MA, Rhoades CC, Heneghan L (2008) A striking profile: Soil ecological knowledge in restoration management and science. Restoration Ecol 16:604-607. doi: 10.1111/j.1526-100X.2008.00490.x

10. Lane DR, BassiriRad H (2005) Diminishing spatial heterogeneity in soil organic matter across a prairie restoration chronosequence. Restoration Ecol 13:403-412. doi: 10.1111/j.1526-100X.2005.00050.x

11. Wang L, Coles N, Wu C, Wu J (2014) Effect of long-term reclamation on soil properties on a coastal plain, Southeast China. J Coastal Res 296:661-669. doi: 10.2112/JCOASTRES-D-13-00129.1

12. Zuo X, Zhao X, Zhao H, Zhang T, Guo Y, Li Y, Huang Y (2009) Spatial heterogeneity of soil properties and vegetation-soil relationships following vegetation restoration of mobile dunes in Horqin Sandy Land, Northern China. Plant Soil 318:153167. doi: $10.1007 / \mathrm{s} 11104-008-9826-7$

13. Gotelli NJ, Simberloff D (1987) The distribution and abundance of tallgrass prairie plants: A test of the core-satellite hypothesis. Amer Nat 130:18-35. doi: 10.1086/284695

14. Blumenthal DM, Jordan NR, Russelle MP (2003) Soil carbon addition controls weeds and facilitates prairie restoration. Ecol Appl 13:605-615. doi: 10.1890/1051-0761(2003)013[0605:SCACWA]2.0.CO;2

15. Natural Resources Conservation Service (2017) Web Soil Survey.

16. Herrick JE, Jones TL (2002) A dynamic cone penetrometer for measuring soil penetration resistance. Soil Sci Soc Am J 66:1320-1324.

17. Moraes MT de, Debiasi H, Carlesso R, Franchini JC, Silva VR da (2014) Critical limits of soil penetration resistance in a rhodic Eutrudox. Rev Bras Ciênc Solo 38:288-298. doi: 10.1590/S0100-06832014000100029

18. Ayers PD, Perumpral JV (1982) Moisture and density effect on cone index. Trans AS AE 25:1169-1172. doi: $10.13031 / 2013.33691$

19. Halliday D, Resnick R (1963) Physics for students of science and engineering, combined edition. John Wiley and Sons, Inc., New York, NY

20. Blake GR, Hartge KH (1986) Bulk density. In: Klute A (ed) Methods of Soil Analysis, Part 1_Physical and Mineralogical Methods, 2nd Edition. Soil Science Society of America, Madison, WI, pp 363-382

21. Kunze GW, Rich CI (1959) Mineralogical methods. In: Rich CI, Seatz LF, Kunze GW. Certain properties of selected southeastern United States soils and mineralogical procedures for their study. Southern Coop. Series Bul. 61: 135-146.

22. Bouyoucos GJ (1962) Hydrometer method improved for making particle size analyses of soils. Agron J 54:464. doi: 10.2134/agronj1962.00021962005400050028x

23. Fox RL, Weaver JE, Lipps RC (1953) Influence of certain soil-profile characteristics upon the distribution of roots of grasses. Agron J 45:583. doi: 10.2134/agronj1953.00021962004500120001x

24. McCauley A, Jones C, Olson-Rutz K (2017) Soil pH and Organic Matter. Montana State University Extension, Bozeman, MT

25. Delta-T Devices (1996) Thetaprobe Soil Moisture User Manual.

26. R Core Team (2018) R: A language and environment for statistical computing. Foundation for Statistical Computing, Vienna, Austria

27. Wickham H (2009) ggplot2: Elegant Graphics for Data Analysis. Springer-Verlag, New York

28. Bates D, Mächler M, Bolker B, Walker S (2015) Fitting linear mixed-effects models using Ime4. J Stat Softw. doi: 10.18637/jss.v067.i01

29. Kuznetsova A, Brockhoff PB, Bojesen RH (2016) ImerTest. Tests in linear mixed effects models.

30. Halekoh U, Højsgaard S (2014) A Kenward-Roger approximation and parametric bootstrap methods for tests in linear mixed models - The R package pbkrtest. J Stat Softw 59:1-30. doi: 10.18637/jss.v059.i09

31. Natural Resources Conservation Service (2014) Soil Survey Field and Laboratory Methods Manual. United States Department of Agriculture

32. Jastrow JD (1987) Changes in soil aggregation associated with tallgrass prairie restoration. Am J Bot 74:1656-1664. doi: 10.1002/j.1537-2197.1987.tb08765.x 
33. Matamala R, Jastrow JD, Miller RM, Garten CT (2008) Temporal changes in C and N stocks of restored prairie: Implications for C sequestration strategies. Ecol Appl 18:1470-1488. doi: 10.1890/07-1609.1

34. McLauchlan KK, Hobbie SE, Post WM (2006) Conversion from agriculture to grassland builds soil organic matter on decadal timescales. Ecol Appl 16:143-153. doi: 10.1890/04-1650

35. Nelson JDJ, Schoenau JJ, Malhi SS (2008) Soil organic carbon changes and distribution in cultivated and restored grassland soils in Saskatchewan. Nutr Cycl Agroecosyst 82:137-148. doi: 10.1007/s10705-008-9175-1

36. Zilverberg CJ, Heimerl K, Schumacher TE, Malo DD, Schumacher JA, Johnson WC (2018) Landscape dependent changes in soil properties due to long-term cultivation and subsequent conversion to native grass agriculture. CATENA 160:282-297. doi: $10.1016 /$ j.catena.2017.09.020

37. Hutchinson GE (1959) Homage to Santa Rosalia or Why are there so many kinds of animals? Amer Nat 93:145-159.

38. Collins B, Wein G (1998) Soil heterogeneity effects on canopy structure and composition during early succession. Plant Ecol 138:217-230.

39. Baer SG, Blair JM, Collins SL, Knapp AK (2004) Plant community responses to resource availability and heterogeneity during restoration. Oecologia 139:617-629. doi: 10.1007/s00442-004-1541-3

40. Kucharik CJ (2007) Impact of prairie age and soil order on carbon and nitrogen sequestration. Soil Sci Soc Am J 71:430. doi: $10.2136 /$ sssaj2006.0074

41. Yost JL, Egerton-Warburton LM, Schreiner KM, Palmer CE, Hartemink AE (2016) Impact of restoration and management on aggregation and organic carbon accumulation in urban grasslands. Soil Sci Soc Am J 80:992. doi: 10.2136/sssaj2015.10.0383

42. Lamb JA, Fernandez FG, Kalser DE (2014) Understanding Nitrogen in Soils. University of Minnesota Extension

43. Miller JO (2016) Soil pH Affects Nutrient Availability. bttps:/ / extension.umd.edu/learn/soil-ph-affects-nutrient-availability.

44. Brye KR, Norman JM, Gower ST (2002) Assessing the progress of a tallgrass prairie restoration in southern Wisconsin. Am Midl Nat 148:218. doi: 10.1674/0003-0031(2002)148[0218:ATPOAT]2.0.CO;2

45. Laboski, CAM., Peters JB, Bundy, LG (2017) Nutrient application guidelines for field, vegetable, and fruit crops. Extension Publication A2809. University of Wisconsin - Madison.

46. Aciego Pietri JC, Brookes PC (2008) Relationships between soil pH and microbial properties in a UK arable soil. Soil Biol Biochem 40:1856-1861. doi: 10.1016/j.soilbio.2008.03.020

47. Jangid K, Williams MA, Franzluebbers AJ, Blair JM, Coleman DC, Whitman WB (2010) Development of soil microbial communities during tallgrass prairie restoration. Soil Biol Biochem 42:302-312. doi: 10.1016/j.soilbio.2009.11.008

48. Card SM, Quideau SA (2010) Microbial community structure in restored riparian soils of the Canadian prairie pothole region. Soil Biol Biochem 42:1463-1471. doi: 10.1016/j.soilbio.2010.05.010

49. Swab RM, Lorenz N, Byrd S, Dick R (2017) Native vegetation in reclamation: Improving habitat and ecosystem function through using prairie species in mine land reclamation. Ecol Eng 108:525-536. doi: 10.1016/j.ecoleng.2017.05.012

50. McKinley VL, Peacock AD, White DC (2005) Microbial community PLFA and PHB responses to ecosystem restoration in tallgrass prairie soils. Soil Biol Biochem 37:1946-1958. doi: 10.1016/j.soilbio.2005.02.033

51. David MB, McIsaac GF, Darmody RG, Omonode RA (2009) Long-term changes in Mollisol organic carbon and nitrogen. J Environ Qual 38:200. doi: 10.2134/jeq2008.0132

52. Rosenzweig ST, Carson MA, Baer SG, Blair JM (2016) Changes in soil properties, microbial biomass, and fluxes of C and N in soil following post-agricultural grassland restoration. Appl Soil Ecol 100:186-194. doi: 10.1016/j.apsoil.2016.01.001

53. Camill P, McKone MJ, Sturges ST, Severud WJ, Ellis E, Limmer J, Martin CB, Navratil RT, Purdie AJ, Sandel BS, Talukder $\mathrm{S}$, Trout A (2004) Community- and ecosystem-level changes in a species-rich tallgrass prairie restoration. Ecol Appl14:1680 1694. doi: 10.1890/03-5273

54. Adams WA (1973) The effect of organic matter on the bulk and true densities of some uncultivated podzolic soils. J Soil Sci 24:10-17. doi: 10.1111/j.1365-2389.1973.tb00737.x

55. Natural Resources Conservation Service Bulk Density/Moisture/Aeration. United States Department of Agriculture

56. Johnston MR, Balster NJ, Zhu J (2016) Impact of residential prairie gardens on the physical properties of urban soil in Madison, Wisconsin. J Environ Qual 45:45-52. doi: 10.2134/jeq2015.02.0093

57. Chesson P (2000) General theory of competitive coexistence in spatially-varying environments. Theor Popul Bio 58:211-237. doi: $10.1006 /$ tpbi.2000.1486

58. Williams BM, Houseman GR (2014) Experimental evidence that soil heterogeneity enhances plant diversity during community assembly. J Plant Ecol 7:461-469. doi: 10.1093/jpe/rtt056

59. Chandrasoma JM, Udawatta RP, Anderson SH, Thompson AL, Abney MA (2016) Soil hydraulic properties as influenced by prairie restoration. Geoderma 283:48-56. https://doi.org/10.1016/j.geoderma.2016.08.001 


\section{ABOUT THE STUDENT AUTHOR}

Krista Marshall performed this study during the summer of 2017 while working as an undergraduate research student in the Balster Lab and finishing her degree in Biological Systems Engineering and Environmental Studies at the University of Wisconsin - Madison. This study inspired Krista to pursue a graduate degree focused on soil science and food systems, her two primary areas of interest. She is currently enrolled in a Ph.D. program in horticulture and agronomy at the University of California Davis.

\section{PRESS SUMMARY}

Approaches for evaluating the progress of prairie restorations tend to focus on aboveground properties. As a result, how belowground properties impact the establishment and trajectory of restorations remains unclear. On this premise, we compared physiochemical soil properties of two adjacent parcels, one successful and one not, within a 13-year-old prairie restoration. We found that many soil properties differed (i.e., percent sand, percent silt, soil pH, and total nitrogen) markedly between these two parcels. However, two soil properties that often correlate with restoration progress (increased soil organic matter and decreased bulk density) in similar studies did not do so at our site. Additionally, only total nitrogen was more spatially heterogeneous in unrestored parcel versus the other, which did not support the second hypothesis. These results emphasize the importance of including soil properties in evaluations of prairie restorations as well as their differential role in inhibiting or supporting restoration success. 